\title{
Sodium Fluctuations and Mortality in a General Hospitalized Population
}

\author{
Gianmarco Lombardi ${ }^{a-c}$ Pietro Manuel Ferrarob,c Luca Calvaruso $^{b, c}$ \\ Alessandro Naticchia ${ }^{b, c}$ Silvia D'Alonzo ${ }^{b, c}$ Giovanni Gambaro ${ }^{a-c}$ \\ a Nefrologia, Dipartimento di Medicina, Azienda Ospedaliera Universitaria Integrata di \\ Verona, Verona, Italy; ${ }^{b}$ U.O.C. Nefrologia, Fondazione Policlinico Universitario A. Gemelli \\ IRCCS, Rome, Italy; ' Università Cattolica del Sacro Cuore, Rome, Italy
}

\section{Keywords}

Hyponatremia · Hypernatremia · Hospital mortality · Retrospective study · Survival analysis

\begin{abstract}
Background/Aims: Aim of our study was to describe the association between natremia $(\mathrm{Na})$ fluctuation and hospital mortality in a general population admitted to a tertiary medical center. Methods: We performed a retrospective observational cohort study on the patient population admitted to the Fondazione Policlinico A. Gemelli IRCCS Hospital between January 2010 and December 2014 with inclusion of adult patients with at least $2 \mathrm{Na}$ values available and with a normonatremic condition at hospital admission. Patients were categorized according to all Na values recorded during hospital stay in the following groups: normonatremia, hyponatremia, hypernatremia, and mixed dysnatremia. The difference between the highest or the lowest $\mathrm{Na}$ value reached during hospital stay and the $\mathrm{Na}$ value read at hospital admission was used to identify the maximum $\mathrm{Na}$ fluctuation. Cox proportional hazards models were used to estimate hazard ratios (HRs) for in-hospital death in the groups with dysnatremias and across quartiles of $\mathrm{Na}$ fluctuation. Covariates assessed were age, sex, highest and lowest Na level, Charlson/Deyo score, cardiovascular diseases, cerebrovascular diseases, dementia, congestive heart failure, severe kidney disease, estimated glomerular filtration rate, and number of Na measurements during hospital stay. Results: 46,634 admissions matched inclusion criteria. Incident dysnatremia was independently associated with in-hospital mortality (hyponatremia: HR 3.11, 95\% Cl 2.53, 3.84, $p<0.001$; hypernatremia: HR 5.12, 95\% Cl 3.94, 6.65, $p<0.001$; mixed-dysnatremia: HR 4.94, 95\% Cl 3.08, 7.92, $p<0.001)$. We found a higher risk of in-hos-
\end{abstract}


pital death by linear increase of quartile of $\mathrm{Na}$ fluctuation ( $p$ trend $<0.001$ ) irrespective of severity of dysnatremia ( $\mathrm{HR} 2.34,95 \% \mathrm{Cl} 1.55,3.54, p<0.001$, for the highest quartile of $\mathrm{Na}$ fluctuation compared with the lowest). Conclusions: Incident dysnatremia is associated with higher hospital mortality. Fluctuation of Na during hospital stay is a prognostic marker for hospital death independent of dysnatremia severity.

\section{Introduction}

Dysnatremia is the most common electrolyte disorder in hospitalized patients; it encompasses hyponatremic and hypernatremic conditions. Hyponatremia is a pathological condition defined as a serum sodium $<135 \mathrm{mmol} / \mathrm{L}$. Epidemiological studies report a prevalence in the general population between 1 and 10\% [1,2] and between 15 and 20\% in the hospital setting [3].

Hypernatremia is defined as a serum sodium $>145 \mathrm{mmol} / \mathrm{L}$. It is generally related to water losses with increase of plasma osmolality. It is less frequent than hyponatremia [4] with a reported in-hospital prevalence of up to $7.7 \%$ [5].

Serum sodium is the main cation of extracellular fluid and plays a key role in serum osmolarity.

Although generally asymptomatic, dysnatremia may develop to a severe condition with high morbidity and mortality [6-8]. Severe hypernatremic conditions can lead to brain shrinkage potentially associated with cerebral bleeding, subarachnoid hemorrhage, and death [9].

Hyponatremic encephalopathy with brain injury is one of the most serious diseases following electrolyte disturbance. By contrast, mild to moderate chronic hyponatremia is considered a non-severe disease [6]. However, recent literature suggests that even mild hyponatremia and hypernatremia may have a considerable burden on patient outcomes, being associated with significantly higher mortality and length of hospital stay [10].

Although several studies evaluated the association between dysnatremia and in-hospital death, only a few reported on the association between incident in-hospital dysnatremia and mortality [11-15] and described the relation between sodium variations and patient outcomes $[12,14,15]$.

The aim of our study was to report the incidence of dysnatremia and to analyze the association between development of dysnatremia, magnitude of sodium fluctuations, and in-hospital mortality in a general medical-surgical inpatient population admitted to a tertiary medical center.

\section{Materials and Methods}

\section{Study Population}

We performed a retrospective single-center observational study on the patient population admitted between January 1, 2010, and December 31, 2014, to the Fondazione Policlinico A. Gemelli IRCCS, a tertiary care academic medical center in Rome (Italy). Data extraction and analysis included only adult patients ( $\geq 18$ years) admitted to the hospital during the period of interest with at least 2 sodium measurements available and with a normonatremic condition (sodium values between 135 and $145 \mathrm{mmol} / \mathrm{L}$ ) at hospital admission. All patients admitted to the intensive care units (ICU) during hospital stay were excluded.

Data were extracted from the Hospital's central electronic database using a specific website interface. We retrospectively collected demographic data including sex and age, clinical data, vital status at hospital 


\section{Kidney \\ Blood Pressure Research}

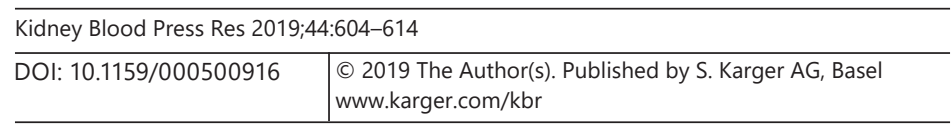

discharge, primary and secondary International Classification of Diseases, Ninth Revision, Clinical Modification (ICD 9 CM) codes at discharge, and laboratory parameters (serum sodium, serum glucose). If a patient had multiple hospital admissions, all of them were included in the analysis.

\section{Definitions}

Hyponatremia was defined as a sodium level $<135 \mathrm{mmol} / \mathrm{L}$. Hypernatremia was defined as a sodium level $>145 \mathrm{mmol} / \mathrm{L}$. Patients were categorized according to all sodium values recorded during hospital stay in the following dysnatremic groups: hyponatremia (lowest/highest sodium values during hospital stay $<135$ and $\leq 145 \mathrm{mmol} / \mathrm{L}$, respectively), hypernatremia (lowest/highest sodium values $\geq 135$ and $>145$ $\mathrm{mmol} / \mathrm{L}$ ), mixed dysnatremia (lowest/highest sodium values $<135$ and $>145 \mathrm{mmol} / \mathrm{L}$ ), normonatremia (lowest/highest sodium values $\geq 135$ and $\leq 145 \mathrm{mmol} / \mathrm{L}$ ). The difference between the highest or lowest sodium value reached during hospital stay and the sodium value at hospital admission was used to identify the sodium fluctuation.

Sodium levels were corrected for the dilutional effect associated with hyperglycemia using validated methods $[16,17]$.

\section{Outcomes and Covariates}

The outcome of interest was in-hospital mortality. Our exposures of interest were the groups of dysnatremia and quartiles of sodium fluctuation. Covariates assessed to control confounding were age, sex, highest and lowest sodium level reached during hospital stay, cardiovascular diseases, cerebrovascular diseases, diabetes, severe kidney disease, dementia, congestive heart failure, estimated glomerular filtration rate (eGFR), malignancies, number of measurements, and Charlson/Deyo comorbidity index score [18]. ICD 9 CM codes were used to identify all comorbid conditions (diabetes: ICD 9 CM 250.1-250.7; cardiovascular diseases: ICD 9 CM 390-459; cerebrovascular diseases: ICD 9 CM 430-438; dementia: ICD 9 CM 290; malignancies: ICD 9 CM 140-239; liver diseases: ICD 9 CM 571.2, 571.4-571.6, 572.2-572.8). Severe kidney disease was identified at hospital admission as an eGFR $<15 \mathrm{~mL} / \mathrm{min} / 1.73 \mathrm{~m}^{2}$. eGFR was estimated according to the Chronic Kidney Disease Epidemiology Collaboration creatinine-based equation [19].

\section{Statistical Analysis}

Continuous variables were described using means (SDs) or medians (interquartile ranges) and categorical variables as counts (percentages). Categorical variables were compared using the chi-square test. Continuous variables were compared using Student $t$ test or Mann-Whitney test as appropriate. The normality of the data distribution was assessed by visually inspecting the histograms and Q-Q plots.

Cox proportional hazards models were used to estimate unadjusted and adjusted hazard ratios (HRs) and $95 \%$ CIs for in-hospital death among the groups of dysnatremias (with the normonatremic group used as the reference) and across quartiles of sodium fluctuation (expressed as percentage and absolute values; the lowest quartile was used as the reference). Time at risk was calculated from the date of hospital admission up to the date of in-hospital death or discharge. All hospitalizations were censored at 60 days of hospital stay.

We assessed nonlinear relationships as well as the potential effect of the velocity (rate) of sodium changes by calculating the rate of change in $\mathrm{mmol} / \mathrm{L}$ per $24 \mathrm{~h}$ and performing an analysis of the sodium slope and in-hospital death in the dysnatremic groups using restricted cubic splines (R studio, "rms" package [20]). Four knots were used at 5th, 25th, 75th, and 95th percentiles of the sodium fluctuation rate distribution. The sodium slope was calculated from an ordinary least-square regression model using all available sodium measurements for each patient between the sodium value at hospital admission and the highest or lowest sodium value reached during hospital stay.

All analyses incorporated standard errors clustered by patient identity to account for within-patient correlations.

A $p$ value $<0.05$ was considered as statistically significant in all analyses.

All analyses were conducted using R version 3.4.4 (R Foundation for Statistical Computing, Vienna University of Economics and Business). 
Kidney

Blood Pressure

Research
Kidney Blood Press Res 2019;44:604-614

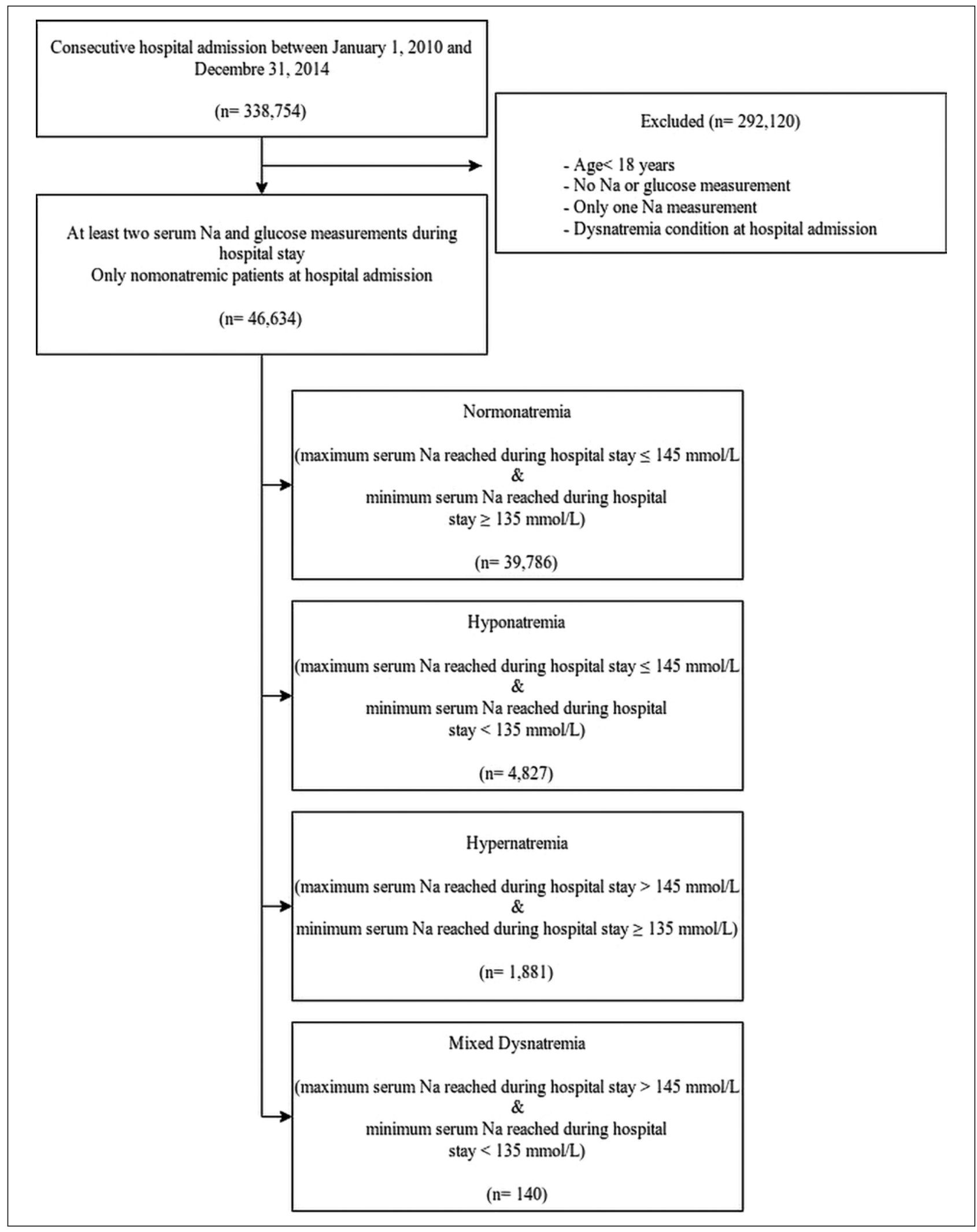

Fig. 1. Flowchart of the study. 
Table 1. Demographic and clinical characteristics of study cohort at first hospital admission by serum sodium status

\begin{tabular}{lccc}
\hline & Normonatremic group & Dysnatremic group & $p$ value \\
\hline Number & 31,425 & 5,022 & \\
Age, years & $59.8(17.8)$ & $67.0(16.3)$ & $<0.001$ \\
Gender, males & $13,883(44.2)$ & $2,436(48.5)$ & $<0.001$ \\
Charlson score & & & $<0.001$ \\
$\quad$ r & $25,045(79.7)$ & $3,449(68.7)$ & \\
$\quad 1$ & $4,073(13.0)$ & $925(18.4)$ & \\
$\quad 1,299(4.1)$ & $327(6.5)$ & $<0.001$ \\
$\quad>2$ & $1,008(3.2)$ & $321(6.4)$ & $<.060$ \\
Charlson score & $0.3(0.9)$ & $0.6(1.2)$ & $<0.001$ \\
Diabetes & $307(1.0)$ & $63(1.3)$ & $<0.001$ \\
Cardiovascular disease & $10,485(33.4)$ & $2,090(41.6)$ & $<0.001$ \\
Congestive heart failure & $1,126(3.6)$ & $316(6.3)$ & $<0.001$ \\
Malignancies & $10,898(34.7)$ & $2,096(41.7)$ & $<0.001$ \\
Cerebrovascular disease & $2,037(6.5)$ & $440(8.8)$ & $<0.001$ \\
Liver disease & $673(2.1)$ & $203(4.0)$ & $<0.001$ \\
Dementia & $133(0.4)$ & $50(1.0)$ & \\
Severe kidney disease & $412(1.3)$ & $70.7(29.4)$ & \\
eGFR & $79.7(27.2)$ & &
\end{tabular}

Values are presented as mean (SD) or $n(\%)$.

eGFR, estimated glomerular filtration rate.

\section{Results}

\section{Demographics}

Between January 1, 2010, and December 31, 2014, 338,754 adult patients were admitted to the hospital. Overall, 46,634 admissions from 36,447 unique patients matched inclusion criteria (Fig. 1). There were 6,848 incident dysnatremic admissions (14.7\%). The baseline characteristics of the cohort (referred to the first hospital admission for each patient) are shown in Table 1. As expected, compared with normonatremic patients, dysnatremic patients were older and had higher prevalence of comorbidities (mean Charlson/Deyo score comorbidity index: 0.6 [SD 1.2] vs. 0.3 [SD 0.9], $p<0.001$ ). Specifically, we found a higher prevalence of cardiovascular diseases ( 41.6 vs. $33.4 \%, p<0.001$ ), cerebrovascular diseases ( 8.8 vs. $6.5 \%$, $p<0.001$ ), severe kidney diseases (3.4 vs. $1.3 \%, p<0.001$ ) in the dysnatremic groups. The characteristics of the entire cohort stratified by quartiles of percentage sodium fluctuation are reported in Table 2 .

\section{Outcomes}

Incident Dysnatremia and In-Hospital Death

Incident dysnatremia was associated with increased risk of in-hospital death (Table 3): the incidence of in-hospital death among dysnatremic patients was $4.6 \%$ (subgroup analysis: incident hyponatremia 3.9\%; incident hypernatremia 5.4\%; mixed-dysantremia mortality of $14.2 \%$ ) compared with $0.5 \%$ in patients who did not develop dysnatremia during hospital stay.

In multivariate analysis, incident dysnatremia was independently associated with in-hospital death (hyponatremia HR 3.11, 95\% CI 2.53, 3.84, $p<0.001$; hypernatremia: HR 5.12, 95\% CI 3.94, 6.65, $p<0.001$; mixed-dysnatremia: HR 4.94, 95\% CI 3.08, 7.92, $p<0.001$ ). Patients with hypernatremia showed increased risk for in-hospital death compared with hyponatremic patients (HR 1.64, 95\% CI 1.27, 2.12, $p<0.001$ ). 
Table 2. Demographic and clinical characteristics of study cohort at first hospital admission by quartile of sodium fluctuation

\begin{tabular}{lcccc}
\hline & $\begin{array}{l}\text { 1st quartile } \\
(<0.7 \%)\end{array}$ & $\begin{array}{c}\text { 2nd quartile } \\
(0.7-2.1 \%)\end{array}$ & $\begin{array}{c}\text { 3rd quartile } \\
(2.1-2.9 \%)\end{array}$ & $\begin{array}{c}\text { 4th quartile } \\
(>2.9 \%)\end{array}$ \\
\hline Number & 9,841 & 9,667 & 8,420 & 8,519 \\
Age, years & $58.3(17.9)$ & $60.5(17.7)$ & $60.5(17.8)$ & $64.1(17.2)$ \\
Gender, males & $4,266(43.3)$ & $4,336(44.9)$ & $3,773(44.8)$ & $3,944(46.3)$ \\
Charlson score & & & & \\
$\quad 0$ & $8,015(81.4)$ & $7,620(78.8)$ & $6,599(78.4)$ & $6,289(73.8)$ \\
$\quad 1$ & $1,252(12.7)$ & $1,324(13.7)$ & $1,145(13.6)$ & $1,295(15.2)$ \\
$\quad 2$ & $321(3.3)$ & $391(4.0)$ & $388(4.6)$ & $501(5.9)$ \\
$\quad>2$ & $253(2.6)$ & $332(3.4)$ & $288(3.4)$ & $434(5.1)$ \\
Charlson score & $0.3(0.8)$ & $0.4(0.9)$ & $0.4(0.9)$ & $0.5(1.0)$ \\
Diabetes & $78(0.8)$ & $93(1.0)$ & $93(1.1)$ & $113(1.3)$ \\
Cardiovascular disease & $3,202(32.5)$ & $3,357(34.7)$ & $2,862(34.0)$ & $3,098(36.4)$ \\
Congestive heart failure & $261(2.7)$ & $369(3.8)$ & $335(4.0)$ & $421(4.9)$ \\
Malignancies & $3,164(32.2)$ & $3,353(34.7)$ & $3,071(36.5)$ & $3,508(41.2)$ \\
Cerebrovascular disease & $643(6.5)$ & $633(6.5)$ & $490(5.8)$ & $692(8.1)$ \\
Liver disease & $191(1.9)$ & $232(2.4)$ & $221(2.6)$ & $236(2.8)$ \\
Dementia & $29(0.3)$ & $44(0.5)$ & $34(0.4)$ & $62(0.7)$ \\
Severe kidney disease & $66(0.7)$ & $124(1.3)$ & $136(1.6)$ & $235(2.8)$ \\
eGFR & $82.1(25.6)$ & $78.9(27.0)$ & $78.5(27.9)$ & $73.8(29.3)$ \\
\hline
\end{tabular}

Values are presented as mean (SD) or $n(\%)$.

eGFR, estimated glomerular filtration rate.

Table 3. Association between serum sodium status and in-hospital death

\begin{tabular}{|c|c|c|c|c|}
\hline & Normonatremia & Hyponatremia & Hypernatremia & Mixed dysnatremia \\
\hline Admissions, $n$ & 39,786 & 4,827 & 1,881 & 140 \\
\hline Patients, $n$ & 31,425 & 3,466 & 1,450 & 106 \\
\hline In-hospital death, $n(\%)$ & $144(0.5)$ & $135(3.9)$ & $79(5.4)$ & $15(14.2)$ \\
\hline $\begin{array}{l}\text { Univariate HR }(95 \% \mathrm{CI}) \\
\quad p \text { value }\end{array}$ & $\begin{array}{l}1.00 \\
\text { Reference }\end{array}$ & $\begin{array}{l}3.93(3.21,4.80) \\
<0.001\end{array}$ & $\begin{array}{l}7.04(5.48,9.05) \\
<0.001\end{array}$ & $\begin{array}{l}8.73(5.63,13.54) \\
<0.001\end{array}$ \\
\hline $\begin{array}{l}\text { Multivariate HR }(95 \% \mathrm{CI})^{*} \\
\quad p \text { value }\end{array}$ & $\begin{array}{l}1.00 \\
\text { Reference }\end{array}$ & $\begin{array}{l}3.11(2.53,3.84) \\
<0.001\end{array}$ & $\begin{array}{l}5.12(3.94,6.65) \\
<0.001\end{array}$ & $\begin{array}{l}4.94(3.08,7.92) \\
<0.001\end{array}$ \\
\hline $\begin{array}{l}\text { Multivariate HR }(95 \% \mathrm{CI})^{*} \\
\quad p \text { value }\end{array}$ & $\begin{array}{l}0.32(0.26,0.40) \\
<0.001\end{array}$ & $\begin{array}{l}1.00 \\
\text { Reference }\end{array}$ & $\begin{array}{l}1.64(1.27,2.12) \\
<0.001\end{array}$ & $\begin{array}{l}1.59(0.99,2.54) \\
0.056\end{array}$ \\
\hline $\begin{array}{l}\text { Multivariate HR }(95 \% \mathrm{CI})^{*} \\
\quad p \text { value }\end{array}$ & $\begin{array}{l}0.20(0.15,0.25) \\
<0.001\end{array}$ & $\begin{array}{l}0.61(0.47,0.78) \\
<0.001\end{array}$ & $\begin{array}{l}1.00 \\
\text { Reference }\end{array}$ & $\begin{array}{l}0.96(0.59,1.58) \\
0.886\end{array}$ \\
\hline $\begin{array}{l}\text { Multivariate HR }(95 \% \mathrm{CI})^{*} \\
\quad p \text { value }\end{array}$ & $\begin{array}{l}0.20(0.13,0.32) \\
<0.001\end{array}$ & $\begin{array}{l}0.63(0.39,1.01) \\
0.056\end{array}$ & $\begin{array}{l}1.04(0.63,1.69) \\
0.886\end{array}$ & $\begin{array}{l}1.00 \\
\text { Reference }\end{array}$ \\
\hline
\end{tabular}

*Adjusted for baseline covariates (age, sex, Charlson/Deyo Score, diabetes, cardiovascular disease, congestive heart failure, malignancies, eGFR, severe kidney disease, cerebrovascular disease, dementia, liver diseases, number of sodium measurements).

$\mathrm{HR}$, hazard ratio; eGFR, estimated glomerular filtration rate. 
Table 4. Association between quartiles of sodium fluctuation (expressed as percentage) and in-hospital death

\begin{tabular}{|c|c|c|c|c|c|}
\hline & $\begin{array}{l}\text { 1st quartile } \\
(<0.7 \%)\end{array}$ & $\begin{array}{l}\text { 2nd quartile } \\
(0.7-2.1 \%)\end{array}$ & $\begin{array}{l}\text { 3rd quartile } \\
(2.1-2.9 \%)\end{array}$ & $\begin{array}{l}\text { 4th quartile } \\
(>2.9 \%)\end{array}$ & $\begin{array}{l}p \text { value } \\
\text { trend }\end{array}$ \\
\hline Admissions, $n$ & 12,109 & 12,165 & 10,890 & 11,470 & \\
\hline Patients, $n$ & 9,841 & 9,667 & 8,420 & 8,519 & \\
\hline In-hospital death, $n(\%)$ & $22(0.2)$ & $33(0.3)$ & $55(0.7)$ & $208(2.4)$ & \\
\hline $\begin{array}{l}\text { Univariate HR }(95 \% \mathrm{CI}) \\
\quad p \text { value }\end{array}$ & $\begin{array}{l}1.00 \\
\text { Reference }\end{array}$ & $\begin{array}{l}1.22(0.77,1.92) \\
0.396\end{array}$ & $\begin{array}{l}1.88(1.24,2.83) \\
0.003\end{array}$ & $\begin{array}{l}4.72(3.28,6.78) \\
<0.001\end{array}$ & $<0.001$ \\
\hline $\begin{array}{l}\text { Multivariate HR }(95 \% \mathrm{CI})^{*} \\
\quad p \text { value }\end{array}$ & $\begin{array}{l}1.00 \\
\text { Reference }\end{array}$ & $\begin{array}{l}1.03(0.65,1.63) \\
0.899\end{array}$ & $\begin{array}{l}1.51(0.99,2.31) \\
0.057\end{array}$ & $\begin{array}{l}2.34(1.55,3.54) \\
<0.001\end{array}$ & $<0.001$ \\
\hline
\end{tabular}

* Adjusted for baseline covariates (age, sex, Charlson/Deyo Score, diabetes, cardiovascular disease, congestive heart failure, malignancies, eGFR, severe kidney disease, cerebrovascular disease, dementia, liver diseases, the lowest and the highest serum sodium levels reached during hospital stay, number of sodium measurements).

HR, hazard ratio; eGFR, estimated glomerular filtration rate.

Table 5. Association between quartile of sodium fluctuation (expressed as absolute value) and in-hospital death

\begin{tabular}{lllll}
\hline & $\begin{array}{l}\text { 1st quartile } \\
\leq 1 \mathrm{mmol} / \mathrm{L}\end{array}$ & $\begin{array}{l}\text { 2nd quartile } \\
1-3 \mathrm{mmol} / \mathrm{L}\end{array}$ & $\begin{array}{l}\text { 3rd quartile } \\
3-4 \mathrm{mmol} / \mathrm{L}\end{array}$ & $\begin{array}{l}\text { 4th quartile } \\
\text { > mmol/L }\end{array}$ \\
\hline Admissions, $n$ & 12,590 & 17,388 & 5,790 & $\begin{array}{l}p \text { value } \\
\text { trend }\end{array}$ \\
Patients, $n$ & 10,205 & 13,727 & 4,443 & 8,072 \\
In-hospital death, $n(\%)$ & $28(0.3)$ & $56(0.4)$ & $29(0.7)$ & $205(2.5)$ \\
HR crude (95\% CI) & 1.00 & $1.29(0.88,1.88)$ & $1.34(0.85,2.10)$ & $4.08(2.93,5.69)$ \\
$\quad p$ value & Reference & 0.189 & 0.207 & $<0.001$ \\
HR adjusted $(95 \% \mathrm{CI})^{*}$ & 1.00 & $1.08(0.74,1.59)$ & $1.01(0.64,1.61)$ & $1.93(1.30,2.85)$ \\
$\quad$ R value & Reference & 0.685 & 0.965 & 0.001 \\
\hline
\end{tabular}

* Adjusted for baseline covariates (age, sex, Charlson/Deyo Score, diabetes, cardiovascular disease, congestive heart failure, malignancies, eGFR, cerebrovascular disease, dementia, liver diseases, the lowest and the highest serum sodium levels reached during hospital stay, number of sodium measurements).

HR, hazard ratio; eGFR, estimated glomerular filtration rate.

Sodium Fluctuation and Mortality

Tables 4 and 5 report the association between quartiles of sodium fluctuation and in-hospital death.

There was a higher risk of in-hospital death among increasing quartiles of sodium fluctuation ( $p$ value for trend $<0.001$ ).

Multivariate analysis revealed a HR of 2.34 (95\% CI 1.55, 3.54, $p<0.001)$ for in-hospital death in the highest quartile of percentage sodium fluctuation compared with the lowest (Table 4).

Similar results were found when absolute values of sodium fluctuation were used (Table 5).

Figure 2 shows the association between the sodium slope and in-hospital death in incident hyponatremic and hypernatremic patients. Using restricted cubic splines, we found a nonlinear $(p<0.001)$ increase in the risk of in-hospital death with increasing sodium slope. 


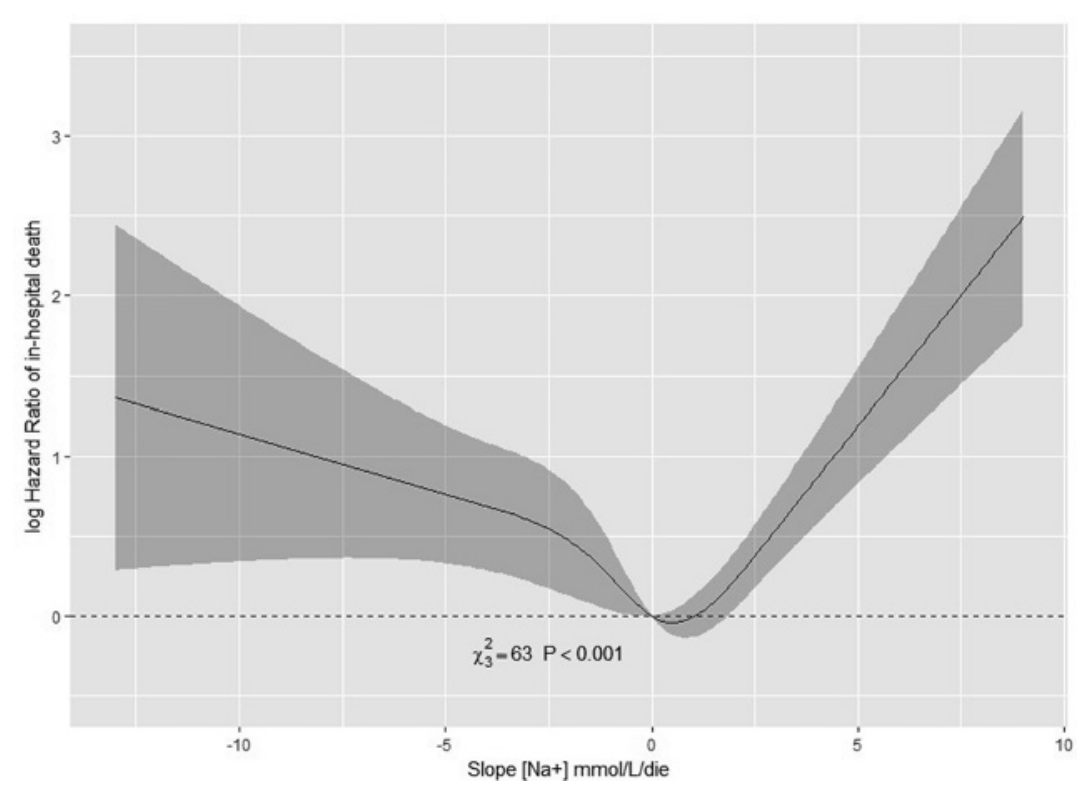

Fig. 2. Association between sodium slope and in-hospital death. Multivariate HRs (95\% CI) of in-hospital death associated with sodium slopes using restricted cubic splines, adjusted for age, sex, Charlson/Deyo Score, diabetes, cardiovascular diseases, congestive heart failure, malignancies, eGFR, severe kidney disease, cerebrovascular disease, dementia, liver diseases, the lowest and the highest serum sodium level reached during hospital stay, number of sodium measurements. HR, hazard ratio.

\section{Discussion/Conclusion}

In this study, we describe the association between incident dysnatremia and in-hospital death and, to the best of our knowledge for the first time, the association between sodium fluctuation and in-hospital death in a general medical-surgical non-ICU hospitalized population. Incident dysnatremia is confirmed to be an independent risk factor for in-hospital death and sodium fluctuations are associated with increased in-hospital death independent of the severity of dysnatremia.

Dysnatremia is the most common electrolyte disorder. To date, a variety of studies evaluated its epidemiology in hospital patients reporting a quite varied incidence and prevalence especially because it is strongly influenced by the study population (ICU vs. non-ICU). The prevalence of hyponatremia in the hospital setting has been described to range between 12 and $17 \%[5,11,21-23]$ and $40 \%$ in the hospitalized population [24]. Similarly, several studies demonstrated that hypernatremia appeared also to be common at hospital admission ranging from 0.5 to $7.7 \%$ [5, 25-28]. However, most of these studies focused on critically ill ICU patients or analyzed community-acquired dysnatremia observed at hospital admission. Conversely, few studies have investigated hospital-acquired dysnatremia and its incidence during hospital stay. The incidence of in-hospital hyponatremia and hypernatremia has been described ranging from 9.0 to $13.6 \%[11,12]$ and from 1.0 to $9.1 \%[11,12]$, respectively.

In order to describe the incidence of dysnatremia during hospital stay, we considered only normonatremic patients at hospital admission. Here we reported one of the largest retrospective studies focusing on hospital-acquired dysnatremia, with an incidence of hyponatremia and hypernatremia of 10.7 and $4.3 \%$, respectively (Table 3 ). 


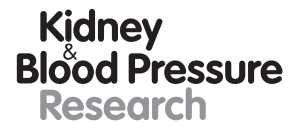

Kidney
Blood Pressure

Research

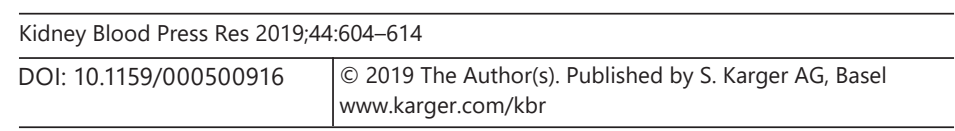

Lombardi et al.: Sodium Fluctuations and In-Hospital Mortality

Explanations for differences in dysnatremia epidemiology compared with previous works include study design (retrospective vs prospective), sample sizes, differences in study population, and in cutoff levels used to define dysnatremia.

Medical interest in dysnatremic conditions is justified by the burden of morbidity and mortality associated with its development. Adverse consequences following dysnatremic conditions have been widely reported in the scientific literature. The association between dysnatremia and mortality is well known in clinical practice and documented in medical literature. Waikar et al. [22] showed that 98,411 prospective patients with hyponatremia had higher in-hospital, 1-year, and 5-year mortality rates than patients without hyponatremia. $\mathrm{Hu}$ et al. [11] demonstrated that all kinds of dysnatremia were independently associated with in-hospital mortality, and mixed dysnatremia (especially "hypo- to hyper") and hypernatremia (especially hospital-acquired and persistent hypernatremia), were strong predictors of mortality. Recent scientific literature suggests also a possible role of borderline or mild forms of dysnatremia on patient outcomes $[5,12,13,22,29,30]$.

In our cohort, $4.6 \%$ of all patients who developed a dysnatremic condition died during hospital stay. In survival analysis, incident dysnatremia was associated with increased in-hospital mortality both in incident hyponatremic and hypernatremic patients. Worthy of notice, the hypernatremic groups had higher risk of death compared with the hyponatremic group.

Our study focused also on sodium fluctuations and mortality. According to data an increase of the blood sodium concentration $>2.9 \%$ from its baseline value is associated with in-hospital death independently of severity of dysnatremia. Furthermore, as expected, a fluctuation occurring too quickly was associated with increased risk of in-hospital death, regardless of sodium value (Fig. 2).

Investigations into sodium fluctuation are still lacking. In particular, the link between sodium fluctuations and in-hospital death is poorly characterized. Until now, this issue has been investigated only in 3 other works $[12,14,15]$. However, those studies were set in ICU in critically ill patients rather than general population patients. Here, focusing on a mixed medical-surgical non-ICU population, we provide increased generalizability to our results, underlining the importance that mild sodium fluctuations $(>2.9 \%$ or $4 \mathrm{mmol} / \mathrm{L}$ from baseline value) and incident dysnatremia carry on patient outcomes.

Similar to previous works, we found a significant association between severity of dysnatremia and mortality. However, while the link between the most severe forms of dysnatremia and mortality has a strong rationale, data on the risk associated with small sodium fluctuations are lacking and the mechanism leading to higher mortality are still unclear. According to our data, a sodium fluctuation just a bit over $4 \mathrm{mmol} / \mathrm{L}$ from baseline was significantly associated with higher in-hospital death. As recently elucidated by a consensus statement from the Italian Society of Endocrinology, Italian Society of Nephrology and the Italian Association of Medical Oncology electrolytes disorders (especially in hyponatremic status) are frequently associated with cardiovascular, liver, malignancies, renal diseases (as well as showed in our study) [31]. It is possible that sodium fluctuation is a potential marker of underlying disease severity. In fact, in our data, we report a higher baseline prevalence of cerebrovascular, renal, and cardiovascular diseases in the highest quartile of sodium fluctuation, all conditions characterized by deranged osmolality control. A direct effect of dysnatremia and mild sodium fluctuations on mortality could also be hypothesized. Sodium is not only the main determinant of plasma osmolality [32] but it also plays a key role in several biochemical and electrical processes within the body [33]. However, our study was not designed to elucidate a possible causal relationship between sodium fluctuations and in-hospital death. Because of the retrospective observational study design, here we can only document an association between exposures and outcomes and only speculate on potential mechanisms. 


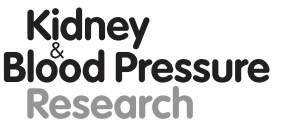

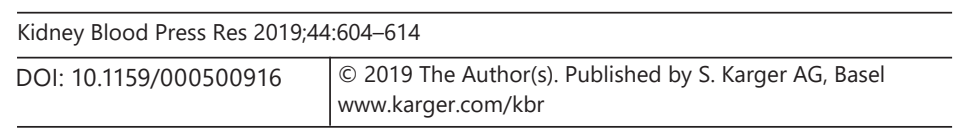

Lombardi et al.: Sodium Fluctuations and In-Hospital Mortality

Our work has several limitations. First, it is a retrospective study conducted on a single hospital center; hence, generalizability of our results could be limited. However, we could include in our analysis admissions from all kinds of medical and surgical wards, which in part improves external validity of our findings. We have no information on causes of dysnatremia and treatments administered during hospital stay, so we could not correct our outcomes for different causes of dysnatremia. Furthermore, we used administrative codes for identification of all comorbid conditions; however, to account for comorbidities, we used the Charlson/Deyo score, a validated method of categorizing comorbidities of patients based on the ICD diagnosis codes from administrative data.

Regarding the strengths of our study, to date this is one of the largest retrospective works on the epidemiology of incident dysnatremia and in-hospital death and, to the best of our knowledge, our work describes for the first time the impact of sodium fluctuations on in-hospital death in a general hospitalized population.

What we would emphasize with our study is the importance that even mild variations in sodium levels have on patient outcomes. It is necessary to pay attention to both small and rapid sodium fluctuations, even when in a normonatremic range.

In summary: (i) incident dysnatremia is associated with increased in-hospital death; (ii) incident hypernatremia is associated with higher mortality than hyponatremia; (iii) sodium fluctuations during hospital stay is a potential predictor of in-hospital death independent of dysnatremia severity.

\section{Statement of Ethics}

The Ethics committee of Fondazione Policlinico Universitario A. Gemelli IRCCS approved the research protocol.

\section{Disclosure Statement}

The authors have no conflicts of interest to declare.

\section{Author Contributions}

G.G., P.M.F., and G.L. contributed to the research idea and study design. G.L. contributed to data acquisition. G.G., P.M.F., and G.L. contributed to data analysis/interpretation. P.M.F. and G.L. contributed to statistical analysis. G.L. and L.C. drafted the paper. G.G., P.M.F., A.N., and S.D.A. contributed to supervision. Each author contributed important intellectual content during manuscript drafting for the overall work.

\section{References}

1 Mohan S, Gu S, Parikh A, Radhakrishnan J. Prevalence of hyponatremia and association with mortality: results from NHANES. Am J Med. 2013 Dec;126(12):1127-37.e1.

2 Miller M. Hyponatremia and arginine vasopressin dysregulation: mechanisms, clinical consequences, and management. J Am Geriatr Soc. 2006 Feb;54(2):345-53.

3 Spasovski G, Vanholder R, Allolio B, Annane D, Ball S, Bichet D, et al.: Clinical practice guideline on diagnosis and treatment of hyponatraemia. Nephrol Dial Transplant. 2014;29 Suppl 2:i1-i39.

4 Kumar S, Berl T. Sodium. Lancet. 1998 Jul;352(9123):220-8. 


\section{Kidney \\ Blood Pressure \\ Research}

\begin{tabular}{l|l}
\hline Kidney Blood Press Res 2019;44:604-614 \\
\hline DOI: 10.1159/000500916 & $\begin{array}{l}\text { @ 2019 The Author(s). Published by S. Karger AG, Basel } \\
\text { www.karger.com/kbr }\end{array}$ \\
\hline
\end{tabular}

5 Funk GC, Lindner G, Druml W, Metnitz B, Schwarz C, Bauer P, et al. Incidence and prognosis of dysnatremias present on ICU admission. Intensive Care Med. 2010 Feb;36(2):304-11.

6 Moritz ML, Ayus JC: The pathophysiology and treatment of hyponatraemic encephalopathy: an update. Nephrol Dial Transplant. 2003;18(12):2486-91.

7 Ayus JC, Achinger SG, Arieff A. Brain cell volume regulation in hyponatremia: role of sex, age, vasopressin, and hypoxia. Am J Physiol Renal Physiol. 2008 Sep;295(3):F619-24.

8 Ayus JC, Wheeler JM, Arieff AI. Postoperative hyponatremic encephalopathy in menstruant women. Ann Intern Med. 1992 Dec;117(11):891-7.

9 Adrogué HJ, Madias NE. Hypernatremia. N Engl J Med. 2000 May;342(20):1493-9.

10 Stelfox HT, Ahmed SB, Khandwala F, Zygun D, Shahpori R, Laupland K. The epidemiology of intensive care unit-acquired hyponatraemia and hypernatraemia in medical-surgical intensive care units. Crit Care. 2008; 12(6):R162.

$11 \mathrm{Hu}$ J, Wang Y, Geng X, Chen R, Zhang P, Lin J, et al. Dysnatremia is an Independent Indicator of Mortality in Hospitalized Patients. Med Sci Monit. 2017 May;23:2408-25.

12 Sakr Y, Rother S, Ferreira AM, Ewald C, Dünisch P, Riedemmann N, et al. Fluctuations in serum sodium level are associated with an increased risk of death in surgical ICU patients. Crit Care Med. 2013 Jan;41(1):133-42.

13 Wald R, Jaber BL, Price LL, Upadhyay A, Madias NE. Impact of hospital-associated hyponatremia on selected outcomes. Arch Intern Med. 2010 Feb;170(3):294-302.

14 Marshall DC, Salciccioli JD, Goodson RJ, Pimentel MA, Sun KY, Celi LA, et al. The association between sodium fluctuations and mortality in surgical patients requiring intensive care. J Crit Care. 2017 Aug;40:63-8.

15 Topjian AA, Stuart A, Pabalan AA, Clair A, Kilbaugh TJ, Abend NS, et al. Greater fluctuations in serum sodium levels are associated with increased mortality in children with externalized ventriculostomy drains in a PICU. Pediatr Crit Care Med. 2014 Nov;15(9):846-55.

16 Katz MA. Hyperglycemia-induced hyponatremia-calculation of expected serum sodium depression. N Engl J Med. 1973 Oct;289(16):843-4.

17 Hillier TA, Abbott RD, Barrett EJ. Hyponatremia: evaluating the correction factor for hyperglycemia. Am J Med. 1999 Apr;106(4):399-403.

18 Deyo RA, Cherkin DC, Ciol MA. Adapting a clinical comorbidity index for use with ICD-9-CM administrative databases. J Clin Epidemiol. 1992 Jun;45(6):613-9.

19 Silveiro SP, Araújo GN, Ferreira MN, Souza FD, Yamaguchi HM, Camargo EG. Chronic Kidney Disease Epidemiology Collaboration (CKD-EPI) equation pronouncedly underestimates glomerular filtration rate in type 2 diabetes. Diabetes Care. 2011 Nov;34(11):2353-5.

20 Harrell FE Jr. Regression Modeling Strategies. R package version 4.3-0. 2015.

21 Reynolds RM, Padfield PL, Seckl JR. Disorders of sodium balance. BMJ. 2006 Mar;332(7543):702-5.

22 Waikar SS, Mount DB, Curhan GC. Mortality after hospitalization with mild, moderate, and severe hyponatremia. Am J Med. 2009 Sep;122(9):857-65.

23 Girardeau Y, Jannot AS, Chatellier G, Saint-Jean O. Association between borderline dysnatremia and mortality insight into a new data mining approach. BMC Med Inform Decis Mak. 2017 Nov;17(1):152.

24 Sedlacek M, Schoolwerth AC, Remillard BD. Electrolyte disturbances in the intensive care unit. Semin Dial. 2006 Nov-Dec;19(6):496-501.

25 Polderman KH, Schreuder WO, Strack van Schijndel RJ, Thijs LG. Hypernatremia in the intensive care unit: an indicator of quality of care? Crit Care Med. 1999 Jun;27(6):1105-8.

26 Hoorn EJ, Betjes MGH, Weigel J, Zietse R: Hypernatraemia in critically ill patients: too little water and too much salt. Nephrol Dial Transplant. 2008;23:1562-68.

27 Bennani SL, Abouqal R, Zeggwagh AA, Madani N, Abidi K, Zekraoui A, et al. [Incidence, causes and prognostic factors of hyponatremia in intensive care]. Rev Med Interne. 2003 Apr;24(4):224-9.

28 O'Donoghue SD, Dulhunty JM, Bandeshe HK, Senthuran S, Gowardman JR. Acquired hypernatraemia is an independent predictor of mortality in critically ill patients. Anaesthesia. 2009 May;64(5):514-20.

29 Kovesdy CP, Lott EH, Lu JL, Malakauskas SM, Ma JZ, Molnar MZ, et al. Hyponatremia, hypernatremia, and mortality in patients with chronic kidney disease with and without congestive heart failure. Circulation. 2012 Feb;125(5):677-84.

30 Darmon M, Diconne E, Souweine B, Ruckly S, Adrie C, Azoulay E, et al. Prognostic consequences of borderline dysnatremia: pay attention to minimal serum sodium change. Crit Care. 2013 Jan;17(1):R12.

31 Sbardella E, Isidori AM, Arnaldi G, Arosio M, Barone C, Benso A, et al.; the: Fluid and Electrolyte Disorders Club of the Italian Society of Endocrinology; Italian Society of Nephrology; and Italian Association of Medical Oncology. Approach to hyponatremia according to the clinical setting: Consensus statement from the Italian Society of Endocrinology (SIE), Italian Society of Nephrology (SIN), and Italian Association of Medical Oncology (AIOM). J Endocrinol Invest. 2018 Jan;41(1):3-19.

32 Hill RW, Wyse GA, Anderson M. Animal Physiology. 2nd ed. Sinauer Associates; 2008.

33 Guyton AC, Hall JE. Textbook of Medical Physiology. 11th ed. Philadelphia: Elsevier Saunders; 2006. 